\title{
A Comparative Study on the Influencing Factors of the Value Added of Cultural Manufacturing and Cultural Service in China
}

\author{
Chang Qing \\ School of Economics, Shang Hai University, Shang Hai, China
}

\section{Email address:}

lchangqingl@163.com

To cite this article:

Chang Qing. A Comparative Study on the Influencing Factors of the Value Added of Cultural Manufacturing and Cultural Service in China. Science Innovation. Vol. 5, No. 4, 2017, pp. 245-249. doi: 10.11648/j.si.20170504.19

Received: March 30, 2017; Accepted: April 15, 2017; Published: June 6, 2017

\begin{abstract}
At present, there are few literatures on the comparative study of cultural manufacturing and cultural services in China. In this paper, the first selection of 45 cultural manufacturing sub-categories in 2013 and 75 cultural services sub-scale enterprises above the cross-sectional data for multiple linear regression studies, comparative cultural manufacturing and cultural services in the total value added and per capita Value - labor productivity aspects of the impact of similarities and differences. The empirical results show that the influence factors of cultural manufacturing and cultural service are somewhat similar, but some are not quite the same. Such as labor factors in the number and wage levels have a greater impact on the cultural manufacturing and cultural services industry; In addition, the fixed assets for the value of cultural manufacturing and labor productivity are very significant, but the fixed assets for culture The impact of the service sector is relatively small, and even the impact on the labor productivity of cultural services can be negligible.
\end{abstract}

Keywords: Cultural Manufacturing Industry, Cultural Service Industry, Added Value, Comparative Study

\section{中国文化制造业与文化服务业增加值影响因素的比较研究}

\section{常青}

经济学院, 上海大学, 上海, 中国

\section{邮箱}

lchangqing1@163.com

摘要：目前对于中国文化制造业与文化服务业进行比较研究的文献很少。本文首次选用了2013年45个文化制造业小类 与75个文化服务业小类规模以上企业的横截面数据进行多元线性回归的研究，比较文化制造业与文化服务业在增加值 总量和人均值一一劳动生产率方面的影响因素有何异同。实证结果表明, 文化制造业与文化服务业的影响因素有些具 有相似性，但有些并不十分相同。例如劳动力因素在数量以及工资水平方面都对文化制造业与文化服务业的具有较大 的影响; 此外, 固定资产对于文化制造业的增加值以及劳动生产率的影响都十分显著, 但是固定资产对于文化服务业 的影响相对就小很多, 甚至对文化服务业劳动生产率的影响都可以忽略不计。

关键词：文化制造业，文化服务业，增加值，比较研究 


\section{1. 引言}

2002年，十六大提出 “支持文化产业快速发展，提高 文化产业在中国的GDP比重, 提高我国综合国力” 这一战 略的提出成为我国文化产业改革、发展的分水岭。此后, 我国文化产业开始进入发展的新时期。在2015年的十三五 的规划建议中正式提出, 要将文化建设作为 “五位一体” 总布局建设中的其中一环, 对全面建成小康社会、实现社 会主义现代化和中华民族伟大复兴, 具有重要的作用。

对于文化产业的定义, 可以说在国际与中国国内都是 同样有着很大的争议, 众说纷纭。在国外至今对于文化产 业的定义也没有一个统一和权威的解释。在我国对于文化 产业的定义, 在文化产业开始研究初期也没有明确的界定。 直至2003年7月, 由中宣部牵头, 成立了国家统计局、文 化部、广电总局、新闻出版总署、国家文物局等单位参加 的 “文化产业统计研究课题组” , 对文化产业的概念进行 科学的界定, 并建立中国的文化产业指标体系。2004年3 月29日, 国家统计局正式出台了《文化及相关产业分类》, 首次从统计学意义上对文化产业的概念和范围进行了权 威界定。我们参照《2004年中国文化及相关产业统计概况》, 文化产业就是为社会公众提供文化、娱乐等精神产品和服 务的活动, 以及与这些活动有关的服务活动的集合。2012 年对标准进行了重新的划分, 分类包括了五个层次, 即: 两个部分、十个大类、 50 个中类、 120 个小类以及小类下 的延伸层。

根据国家统计局的有关文化产业分类，我国的文化产 业又可以分为文化制造业、文化批零业与文化制造业，但 是在根本属性上批零业是属于第三产业服务业的, 因此为 了研究的目的性, 更方便和全面地探讨文化制造业与文化 服务业地特性区别, 在本文地所有研究中都将文化批零业 作为文化服务业地组成部分, 故可以再依据国家统计局地 分类准则将 120 个小类分成 45 个文化制造业小类与 75 个文 化服务业小类。

由于我国对于文化产业的官方全面的统计开始于 2012年, 因此很多之前的学者对于文化产业的研究只是局 限于某些特点小类行业或者更多的侧重于文化服务业, 并 且缺乏数据的佐证。但是, 文化制造业属于我国第二产业 范畴, 文化服务业属于我国第三产业服务业, 只是对于文 化服务业的研究或者某些特定小类行业的研究不足以概 括全部的文化产业, 而数据地缺失更加难以揭示文化制造 业与文化服务业的根本属性区别。因此, 深入地研究文化 制造业与文化服务业的区别既是可以检验现在学术界中 流行的对于文化产业的特性看法, 也有助于深入的了解文 化制造业与文化服务业地个性差异, 进而更好的促进我国 文化产业的发展。

\section{2. 文献综述}

附加值是指企业或者一个行业乃至社会所新创造出 来的价值, 高的附加值意味着在生产过程中赋予了更多的 技术含量或者更多的知识与智力, 一个产品或者一个企业 的附加值与它的利润高低也是成正比的。对于文化产业是
否具有高附加值属性, 我国学者早在 21 世纪初就有这方面 的研究。例如厉无畏 [1] 就提出 “以文化提升上海产业的 附加值和竞争力”。在文献中也有描述, 上海市工业增加 值常年较低的原因是忽视了文化因素和产品的文化竞争 力, 因此要加大文化产业的发展步伐, 推动增加值率的提 高。薛永武 [2] 也是论述了文化产业的经济属性与社会属 性, 其中经济属性包括高附加值等特点, 并且作者进一步 解释这种高附加值是体现了文化产品自身的文化价值, 既 有经济价值也有文化传播的价值。但是，关于文化产业的 附加值属性, 研究最多的领域则是集中在文化服务业或者 文化创意产业两个文化产业的分支上。付小颖 [3]则是基 于对河南省文化服务业发展路径选择的角度, 文化服务业 也是兼具了文化业与服务业的双重属性, 因此具有高附加 值的特点。厉无畏 $[4]$ 也是提出文化创意产业本身的高附 加值性使得发展文化创意产业可以实现经济增长方式的 转变。对于文化产业附加值的实证分析, 可能由于我国本 身对于文化产业全面统计起步的时间较晚, 涉及的文献较 少, 有也基本上集中在我国文化产业下面的小范围几个行 业增加值的研究上。董承华 [5] 以我国动漫的生产为例, 郭新茹 [6]运用实证研究的方法对我国文化产业中的工艺 品、设计类产品等七大类文化产品的总的出口贸易额进行 数据分析。从以上的文献情况来看, 我国对于文化产业附 加值的实证分析很少, 更加少有有关影响因素的实证分析, 更是没有学者进行文化制造业与文化服务业的对比实证 研究。

我国学者目前对于产业劳动生产率的研究很多是集 中在第一、第二与第三产业之间的比较, 都是进行实证研 究得出的结论也基本一致: 第二产业的劳动生产率最高、 第三产业其次、第一产业的劳动生产率是最低的。例如邬 民乐 [7] 与王丽英 [8] 都是以全国范围的劳动生产率为研 究对象, 同时邬民乐还对第三产业的具体行业分类的劳动 生产率做了研究, 得出第三产业中又以 “其他服务行业” 与批发零售贸易餐饮业的劳动生产率最低。在这些研究之 上, 裴长洪 $[9]$ 则是指出在发达国家第三产业的劳动生产 率也仅仅是相近于第二产业, 并解释这种现象是由于第二 产业现在可以通过规模经济实现劳动生产率的提高, 但是 第三产业大都是小规模经营为主。对于文化产业的劳动生 产率的研究, 则是集中在两个方面。第一是横向对比研究, 就是与英美等发达国家或者与其他的发展中国家的劳动 生产率进行比较。雷光华 [10]将我国文化产业与美国文化 产业的劳动生产率进行比较, 得出 2000 年我国文化产业的 劳动生产率为 1286 美元, 而同期美国的为 68210 美元, 不 仅远远低于美国水平, 也低于世界平均水平 5420 美元。池 建宇 [11] 也是以英美发达国家为比较对象, 得出的结论与 雷光华的相同。刘冰 [12]则是另选比较对象, 是对俄罗斯、 印度、巴西、中国和南非五个金砖国家的文化产业的劳动 生产率进行比较分析, 发现仅南非的文化产业劳动生产率 略高于其全行业劳动生产率, 而中国仅仅是二者相近。但 是相比较之下, 美国和韩国的文化产业的劳动生产率都是 要远远超过本国全行业劳动生产率的。对于文化产业劳动 生产率的研究第二个方面就是聚焦在某一个文化行业上, 分析它的劳动生产率。例如梁玢 [13] 对于北京市的文化创 
意产业的劳动生产率进行研究, 得出其低于北京市整体第 三产业劳动生产率的结论, 而且在北京市各个服务行业中 其劳动生产率也仅仅是一般水平。李治堂 [14]的研究视角 更是集中在了出版产业上, 发下我国出版产业的劳动生产 率要远远低于美国出版产业的劳动生产率。通过以上文献 的概述可以发现, 我国对于文化产业劳动生产率的研究很 少, 绝大部分是对整个第二产业或者第三产业整体劳动生 产率的研究。但是基于目前少量的研究可以得出, 我国文 化产业劳动生产率总体发展不尽如人意, 而且并没有表现 出在发达国家那种高劳动生产率的现象。但是, 对于文化 制造与文化服务两个性质不同的分类, 它的劳动生产率影 响因素的异同却几乎没有学者研究。

\section{3. 文化制造业与文化服务业增加值影响因素的 比较分析}

在本章内容中, 运用多元线性回归的方法比较分析对 文化制造业和文化服务业的效率的影响因素, 找出对两者
影响因素的相同与差异之处。考虑到数据的可得性, 本部 分选取了 2013年文化产业全部120个小类（45个文化制造 业与 75 个文化服务业) 规模以上文化企业的数据做了横截 面的多元线性回归分析。

为了分析不同因素对文化制造业和文化服务业的影 响程度的不同, 下面将分别从总额和人均额的角度, 运用 多元线性回归来比较文化制造业和文化服务业增加值所 受影响因素的不同。

\section{1. 文化制造业和文化服务业增加值影响因素的比较分 析}

\subsection{1. 指标选取以及基本分析方法}

在对文化制造业和文化服务业的总额情况进行分析 时, 选取了资产总额、固定资产原价、从业人员数和所有 者权益来做为自变量, 这些因素基本上涵盖了能够对 $\mathrm{y}$ 产 生重大影响的自变量。

表1 增加值影响因素的指标选取。

\begin{tabular}{lllll}
\hline 增加值（亿元） & 资产总计（亿元） & 固定资产原价（亿元） & 从业人员期末人数（千人） & 所有者权益（亿元） \\
\hline $\mathrm{y}$ & $\mathrm{X} 1$ & $\mathrm{X} 2$ & $\mathrm{X} 3$ & $\mathrm{X} 4$ \\
\hline
\end{tabular}

在进行多元线性回归时, 本文将采用逐步法进行变量 引入, 根据方差的分析结果来选择符合判据条件并且对因 变量影响最大的自变量选择进回归模型。根据向前选择法 则进入自变量; 然后根据向后剔除法, 将模型中F检验概 率最小的且符合剔除判据条件的自变量剔除, 重复进行直 到模型中的自变量均符合进入的判据条件, 模型外的自变 量都不符合进入模型的判据为止。

\subsection{2. 文化制造业增加值影响因素的分析}

运用 spss, 按照逐步法引入变量, 首先用 $\mathrm{y}$ 对X1、X2、 $\mathrm{X} 3$ 和X4做回归, 但是在系数表中针对X1和常数项的 $\mathrm{t}$ 检验 并不合格, 因而剔除变量X1之后, 重新做y对X2、X3和X4 的回归。在剔除X1之后的回归中, 在系数表中针对常数项 的 $\mathrm{t}$ 检验并不合格, 因而我们再做 $\mathrm{y}$ 对X2、X3和X4的不含常 数项的多元线性回归。所得结果中所有的剩余三个变量X2、 $X 3$ 和X4均被选入回归模型, 没有被删除的自变量。且 $R^{2}$ 为 0.982 说明模型的相关性较好, $F=759.462, P$ 值 $=0.000$, 说明回归方程显著, X2、X3和X4整体上对 $\mathrm{y}$ 有高度影响。 在单个系数的 $\mathrm{t}$ 检验中, $\mathrm{X} 2 、 \mathrm{X} 3$ 和 $\mathrm{X} 4$ 的 $\mathrm{t}$ 检验的 $\mathrm{P}$ 值均为 0.000 , 因而单个系数也是显著的。因而总量视角下的文 化制造业的多元线性回归模型为:

$$
\mathrm{y}=-0.192 * \mathrm{X} 2+0.510 * \mathrm{X} 3+0.574 * X 4
$$

\section{1.3. 文化服务业增加值影响因素的分析}

运用 $\mathrm{sps}$, 按照逐步法引入变量, 首先用 $\mathrm{y}$ 对X1、X2、 $\mathrm{X} 3$ 和 X4做回归。但是在系数表中针对 X1和常数项的 $\mathrm{t}$ 检验 并不合格, 因而剔除变量X1之后, 重新做 $\mathrm{y}$ 对X2、X3和X4 的回归。所得结果中在系数表中针对常数项的 $\mathrm{t}$ 检验并不 合格, 因而剔除常数项之后, 重新做 $\mathrm{y}$ 对X2、X3和X4的不 含常数项的回归。所得结果中所有的三个变量X2、X3和X4
均被选入回归模型，没有被删除的自变量。且 $R^{2}$ 为 0.896 说明模型的显著性高, $\mathrm{F}=204.736$, $\mathrm{P}$ 值 $=0.000$, 说明回 归方程显著, X2、X3和X4整体上对 $\mathrm{y}$ 有高度影响。因而总 量视角下文化服务业y对X2、X3 和X4的多元线性回归结果 为:

$$
\mathrm{y}=-0.270 * X 2+1.658 * X 3+0.286 * X 4
$$

\subsection{4. 文化制造业和文化服务业增加值影响因素的比较 分析}

由上述分析可得, 在总量的视角下, 文化制造业的多 元线性回归方程为公式 (1) : $\mathrm{y}=-0.192 * \mathrm{X} 2+0.510 * \mathrm{X} 3$ $+0.574 * X 4$ 。文化服务业的多元线性回归方程为为公式 (2) : $\mathrm{y}=-0.270 * \mathrm{X} 2+1.658 * \mathrm{X} 3+0.286 * \mathrm{X} 4$ 。其中X2、 $X 3$ 和X4分别代表固定资产原价、从业人员数和所有者权益。

1）对文化制造业而言：第一，所有者权益（X4）对 增加值影响程度最大, 每多一单位的所有者权益, 增加值 就可以增加 0.574 。行业的净资产越高, 说明行业的资本 实力更雄厚, 股东对企业的支持力度更大。第二, 对增加 值影响力第二的是从业人员数 (X3) , 从业人员每增加一 人, 增加值就增加 0.510 。从业人员数是仅次于资本水平 的第二影响因素, 且影响力与所有者权益相差不大。第三, 影响力最小的是固定资产原价, 且为负值, 说明固定资产 原价每增加一单位, 增加值就会减少 0.270 。一方面, 对 于文化制造业，其资产既有固定资产，也包括版权之类的 无形资产, 固定资产原价的提高会挤压用于购买无形资产 的资金, 从而会对增加值产生负面影响。另一方面, 文化 制造业中人力资本数对增加值也有着很大影响, 固定资产 的原价过高, 也会挤压用于购买劳动力的资金额，从而对 增加值产生负面影响。 
2) 对文化服务业而言: 第一，从业人员数（X3）对 文化服务业的增加值影响最大, 且远远大于其他因素, 从 业人员数每增加 1 , 增加值就会增加 1.658 。这是因为文化 服务业是劳动力密集型行业, 单一劳动力的贡献较大。第 二, 所有者权益 (X4) 对增加值也有一定的影响, 即所有 者权益每增加 1 , 增加值就增加 0.286 。这是因为, 所有者 权益越高, 说明行业的资本实力越强, 产业增加值也就越 高。第三, 固定资产原价对增加值有反向的影响, 即固定 资产原价每增加 1 , 增加值就减少 0.270 。对于文化服务业, 对资产水平的要求相对较低, 而资产需求中更多的是无形 资产，因而固定资产对增加值有反向的影响。

3) 从两个模型比较来看: 第一, 在两个模型中, 均 不包含常数项, 说明当固定资产原价, 从业人员数和所有 者权益为零时, 产业增加值也为零。第二, 在文化制造业 和文化服务业中, 固定资产原价系数为 -0.192 和 -0.270 , 固定资产原价对文化制造业增加值和文化服务业增加值 均有反向的影响, 但是文化服务业的系数的绝对值更大, 这是因为文化制造业对固定资产的需求要大于文化服务 业，而文化服务业对非固定资产等等的需求要大于文化制 造业, 一正一反两个效应叠加, 导致固定资产原价对文化 服务业的反向影响更大。第三, 文化制造业和文化服务业
的从业人员数的系数分别是 0.510 和 1.658 。可以看出从业 人员数对文化制造业和文化服务业都有着较大的正向影 响, 对文化服务业的影响能力更大。说明文化服务业作为 劳动密集型行业对劳动力的需求要大于文化制造业。第四, 所有者权益在文化制造业和文化服务业的系数分别是 0.574 和 0.286 。可以看出，所有者权益对文化制造业的影 响力更大, 这是因为文化制造业和文化服务业对资产水平 特别是无形资产都有一定的需求，但是由于文化制造业对 固定资产需求相对更高, 并且文化服务业可能对于人力资 源的需求更大削弱了对于净资产的需要, 因而净资产对文 化制造业增加值的影响也就更大。

\section{2. 文化制造业和文化服务业劳动生产率影响因素的比 较分析}

\subsection{1. 指标选取以及基本分析方法}

在对文化制造业和文化服务业的劳动生产率 (人均增 加值）情况进行分析时, 我选取了人均资产总额、人均固 定资产原价、人均工资水平和每百元固定资产实现增加值 来做为自变量, 这些因素基本上涵盖了能过对 $\mathrm{y}$ 产生重大 影响的因素。具体情况如下表:

表2 增加值影响因素的指标选取。

\begin{tabular}{|c|c|c|c|c|}
\hline 人均增加值 (千元) & 人均资产总额 (千元) & 人均固定资产原价（千元） & 人均工资水平 (千元) & 每百元固定资产实现增加值（千元） \\
\hline $\mathrm{y}$ & $\mathrm{X} 1$ & X2 & X3 & X4 \\
\hline
\end{tabular}

在本部分的多元线性回归中, 将采用与总量分析中的相同的分析方法, 此处不再赘述。

\subsection{2. 文化制造业劳动生产率影响因素的分析}

运用spss，按照逐步法引入变量，首先用y对X1、X2、 X3和X4做回归, 但是在系数表中针对X1的 t检验并不合格, 因而剔除变量X1之后, 重新做y对X2、X3和X4的回归。所 得结果中所有的剩余三个变量X2、X3和X4均被选入回归模 型, 没有被删除的自变量。 $\mathrm{R}^{2}$ 为 0.821 说明模型的相关性 较好, $F=62.570, P$ 值 $=0.000$, 说明回归方程显著, X2、 $\mathrm{X} 3$ 和 X4整体上对 $\mathrm{y}$ 有高度影响。在单个系数的 $\mathrm{t}$ 检验中, $\mathrm{X} 2$ 、 $\mathrm{X} 3 、 \mathrm{X} 4$ 和常数项的 $\mathrm{t}$ 检验的P值均为 0.000 , 因而单个系数 也是显著的。因而人均量视角下的文化制造业的多元线性 回归模型为:

$$
\mathrm{y}=-78.968+0.208 * \mathrm{X} 2+2.411 * \mathrm{X} 3+0.798 * \mathrm{X} 4
$$

\subsection{3. 文化服务业劳动生产率影响因素的分析}

运用 $\mathrm{spss}$, 按照逐步法引入变量, 首先用 $\mathrm{y}$ 对X1、X2、 $\mathrm{X} 3$ 和 X4做回归。但是在系数表中针对 X2 和X4的 $\mathrm{t}$ 检验并不 合格, 因而剔除变量X2和X4之后, 重新做y对X1和X3的回 归。所得结果中所有的两个变量X1和X3均被选入回归模型, 没有被删除的自变量。 $R^{2}$ 为 0.721 , 说明模型的显著性高, $\mathrm{F}=91.921, \mathrm{P}$ 值 $=0.000$, 说明回归方程显著, X1和X3整体 上对y有高度影响。因而人均量视角下文化服务业y对X1 和X3的多元线性回归结果为:

$$
\mathrm{y}=-110.809+0.056 * X 1+3.114 * X 3
$$

\subsection{4. 文化制造业和文化服务业劳动生产率影响因素的 比较分析}

由上述分析可得, 在人均量视角下的文化制造业的多 元线性回归模型为公式 (3) : $\mathrm{y}=-78.968+0.208 * X 2+$ $2.411 * X 3+0.798 * X 4$ 。文化服务业的多元线性回归方程 为为公式 (4) : $\mathrm{y}=-110.809+0.056 * X 1+3.114 * X 3$ 。 其中X1、X2、X3和X4分别代表人均资产总额、人均固定资 产原价、人均工资水平和每百元固定资产实现增加值。

1) 对文化制造业而言：第一，人均工资水平（X3）对 劳动生产率影响最大, 人均工资水平每增加 1 , 劳动生产率 就可以提高2. 411。这是因为, 工资水平是工作积极性的决 定性因素, 工资水平的提高可以显著刺激工人的劳动生产率。 因而工资的提高就会显著提高行业的劳动生产率。第二, 每 百元固定资产实现增加值 (X4) 是对劳动生产率的第二影响 因素, 每百元固定资产实现增加值每增加 1 , 劳动生产率就 可以提高 0.798 。因为文化制造业是既需要资产也需要劳动 力, 而二者的结合水平也就直接影响了生产率的情况, 每百 元固定资产实现增加值越高, 代表固定资产的利用效率也就 越高, 每个人生产的增加值也就越高。第三, 文化制造业的 最后一个影响因素是人均固定资产原价 (X2)，人均固定资 产原价每提高 1 , 劳动生产率就提高 0.208 。人均固定资产原 价反映了人均占有的固定资产数量, 人均固定资产数量越高, 同样时间生产出来的产品也就越多。

2）对文化服务业而言：第一，人均工资水平（X3） 对劳动生产率影响最大, 因为工资水平的提高可以很大的 激发工人的生产能力, 进而也就在很大程度上决定了劳动 
生产率。第二，文化服务业劳动生产率的第二个影响因素 为人均资产总额 (X1) , 人均资产总额每增加 1 , 劳动生 产率就增加0.056。由于文化服务业对无形资产的需求, 导致人均的资产总额越多, 劳动生产率也就会越高。

3）从两个模型比较来看: 第一, 人均工资水平在文 化制造业劳动生产率模型和文化服务业的劳动生产率模 型中的系数分别是 2.411 和 3.114 。人均工资对两者的劳动 生产率均有着较大影响, 且都是最大的影响因素。这是因 为不论是文化制造业还是文化服务业, 工资水平都是最直 接的提高生产率的因素。第二, 文化制造业的劳动生产率 还受到人均固定资产原价 (X2) 和每百元固定资产实现增 加值 (X4) 的影响, 而文化服务业并不受这两项因素的影 响, 文化服务业对固定资产的需求水平很低, 因而劳动生 产率也就不受固定资产以及固定资产产出效率的影响。第 三, 文化服务业劳动生产率还受到人均资产总额 (X1) 的 影响, 而文化制造的劳动生产率却不受其影响。文化制造 业中的资产大部分都是固定资产，而模型中已经包括了固 定资产的情况。文化服务业不受固定资产的影响，而是资 产总水平的影响更大一些。

\section{4. 结论}

增加值方面: 选取了 4 个指标作为自变量, 分别为资 产总计、固定资产原价、从业人员数以及所有者权益（净 资产）。分析结果发现，总资产对文化制造业与文化服务 业的增加值均没有影响, 其余的 3 个因素中, 对文化制造 业影响最大的是净资产，而对文化服务业影响最大的是从 业人员数，这也说明文化制造业更多的依赖净资产，但是 文化服务业则是较多的依赖劳动力。

劳动生产率方面: 选取了 4 个指标作为自变量分别为 人均资产总额、人均固定资产原价、人均工资水平以及每 百元固定资产实现增加值。分析结果发现, 人均工资水平 对于两者的劳动生产率都有正向作用，但是文化制造业的 劳动生产率还与人均固定资产原价和每百元固定资产实 现增加值有关, 文化服务业的劳动生产率就只与人均资产 总额有关了。对文化制造业劳动生产率影响最大的是人均 固定资产原价，而对文化服务业影响最大的是人均工资水 平, 说明在产出效率上讲, 文化制造业需要更多的固定资 产，而文化服务业则是需要更高的人力资本。

结合文化服务业和文化制造业的产业增加值和劳动 生产率的影响因素分析总体来看: 第一，不论是对文化制 造业还是文化服务业, 劳动力情况都是对增加值和劳动生 产率的重要影响因素, 且除了在文化制造业的增加值是第 二影响因素外, 其他均是第一影响因素。这就说明, 不论 文化制造业还是文化服务业, 劳动力起着至关重要的作用。 但是相比较而言, 文化服务业中劳动力情况的决定能力更 大, 而在文化制造业中, 劳动力的决定能力相对差一些。 第二，固定资产水平以及固定资产的利用效率总体来看是 文化制造业的重要影响因素, 相比较之下对文化服务业的 影响就要弱一些。第三, 所有者权益情况对文化制造业和 文化服务业的增加值均有一定影响, 但是在文化制造业的 影响能力更大。

\section{5. 展望}

本文所采用的数据都是我国2013年统计局的全国范 围规模以上文化企业普查数据。一方面, 只是2013年一年 的数据难以非常清晰地揭示我国文化产业发展的情况, 以 及每个特性指标的每年的变化情况; 另一方面, 本文只是 对文化制造业与文化服务业的影响因素进行了比较, 但是 对于深层次的原因并没有做进一步的探析, 这也是以后可 以尝试的研究方向。

\section{参考文献}

[1] 厉无畏, 王玉梅. 以文化提升上海产业的附加值和竞争力 $[\mathrm{J}]$. 上海经济研究, 2003, 06:52-56。

[2] 薛永武. 论文化产业的经济属性和社会属性 $[J]$. 山东大学 学报 (哲学社会科学版), 2016, 05:32-40。

[3] 付小颖. 河南加快文化服务业发展的路径选择 $[\mathrm{J}]$. 学习论 坛, 2015, 07:63-66。

[4] 厉无畏. 上海创意产业发展的思路与对策 $[\mathrm{J}]$. 上海经济, 2005, S1:66-71。

[5] 董承华. 微笑曲线理论视角下的文化产业发展分析 [J]. 新 视野, 2012, 06:41-44。

[6] 郭新茹, 刘冀, 唐月民. 价值链视角下我国文化产业参与 国际分工现状的实证研究——基于技术含量的测度 [J]. 经 济经纬, 2014, 05:81-86。

[7] 邬民乐. 改革以来中国劳动生产率的增长因素: 基于产业 结构的分析 $[\mathrm{J}]$. 西北人口, 2009, 02:37-41。

[8］王丽英, 刘后平. 产业结构变迁对劳动生产率增长的贡献 及其区域差异- - 基于Shift-share 模型的实证分析 [J]. 西部论坛, 2010, 05:94-100。

[9] 裴长洪. 中国经济转型升级与服务业发展 $[\mathrm{J}]$. 财经问题研 究, 2012, 08:3-9。

[10］雷光华. 关于提升我国文化产业国际竞争力的思考 $[J]$. 湖 南社会科学, 2004, 01:177-180。

[11] 池建宇, 姚林青. 中国文化产业劳动生产率的国际比较一 一基于与英美两国之比较 $[\mathrm{J}]$. 中央财经大学学报, 2010, 11:75-79。

[12] 刘冰. 金砖国家文化产业发展比较研究 [J/OL]. 调研世界, 2016 (01)。

[13] 梁玢. 劳动生产率视角下文化创意产业发展研究一一以北 京市为例 [J]。商业时代, 2014, 15:123-125。

[14] 李治堂. 中美出版产业发展与结构比较分析 $[\mathrm{J}]$. 科技与出 版, 2015, 07:100-105。 